ORIGINAL ARTICLE

\title{
Role of Early Tracheostomy in the Management of Severe Head Injury
}

\author{
ABDUL MAJID, MUHAMMAD FAROOQ, MUHAMMAD SHAKIR \\ ZUBAIR MUSTAFA KHAN, SAJID IQBAL \\ Department of Neurosurgery, PGMI/Lahore General Hospital (LGH), Lahore - Pakistan \\ DOI: https://doi.org/10.36552/pjns.v23i3.355
}

\begin{abstract}
Objective: Patients presenting with severe head injuries in the emergency department necessitate long-term airway management with the help of tracheostomy or translaryngeal intubation. The objective of this study was to compare the role of early and late tracheostomy in patients presenting with severe head injuries.

Material and Methods: This randomized controlled trial study was conducted in the department of neurosurgery, Lahore General Hospital Lahore from March 2018 to August 2018, after taking approval from the ethical committee. A total of one hundred and thirty patients was divided randomly into early (within three days) and late (after three days) tracheostomy groups. After tracheostomy, data regarding acute physiology, age and chronic health evaluation II (APACHE II), the total number of days since ventilation, tracheostomy, weaning, discharge from ICU and hospital, complications and mortality were noted. All the data was entered and analyzed with SPSS 23.0. Quantitative variables were presented as mean and standard deviation, qualitative variables were presented as numbers and percentage. The Chi-square test was applied. A p-value of $\leq 0.05$ was considered significant.
\end{abstract}

Results: The mean age of the patients was $33.13 \pm 2.53$ years. There were 84 males (64.61\%) and 46 females $(35.38 \%)$ in the study. The duration of mechanical ventilation, ICU stay and stay in hospital for early and late tracheostomy groups were $25.68 \pm 2.94$ vs. $33.37 \pm 3.32$ days, $29.42 \pm 2.97$ vs. $38.54 \pm 3.80$ days and $37.20 \pm$ 2.98 vs. $47.15 \pm 3.84$ days respectively. Four patients (3.08\%) and seven patients (5.38\%) suffered from mortality.

Conclusion: Early tracheostomy among the patients presenting with severe head injuries was associated with a better outcome than late tracheostomy.

Keywords: Severe Head Injury, Early Tracheostomy, Late Tracheostomy, Intensive Care Unit.

\section{INTRODUCTION}

Traumatic brain injuries result from abrupt and unbearable mechanical forces leading to contusion, concussion or intracranial bleed. ${ }^{1,2}$ During 2002-2006, in the United States, around fifty thousand patients died among 1.7 million patients presenting in the emergency department with traumatic brain injuries. ${ }^{3}$ Similar kind of figures was noted in low and middleincome countries accounting for 50\% road traffic accidents and $75 \%$ accidents due to fall. ${ }^{4}$ In a multicenter study by Bhatti et al., in Pakistan around 12,125 patients presented in emergency departments with head injuries. 5 The patients presenting in neurosurgery emergency with severe head injury are usually unconscious and have a Glasgow Coma Scale (GCS) score of $\leq 12 .^{6}$ This kind of patients generally need sedatives and analgesics for a longer period of time and can develop certain respiratory problems and complications, which may affect their chances of survival and prognosis. Mostly these patients require ventilatory support with the help of tracheostomy or translaryngeal intubation.

According to some studies, as compared to the prolonged endotracheal intubation, tracheostomy usually has fewer risks by minimizing the need for mechanical ventilation and the total duration of stay in 
the intensive care unit. In a study by Lesnik et al. ${ }^{7}$ and D'Amelio et al., ${ }^{8}$ it was noted that early tracheostomy is more beneficial than late tracheostomy. It was reported that patients who underwent late tracheostomy required ventilation for longer days and they had a higher frequency of pulmonary infections. ${ }^{9}$

However, some studies suggest that tracheostomy may lead to certain complications for example pneumothorax, bleeding, subcutaneous emphysema, infections and in some cases tracheal stenosis. In a study by Kocaeli et al., ${ }^{10}$ it was noted that in early tracheostomy intracranial pressure was increased twice whereas, in late tracheostomy, the increase was seen up to $30 \%$ only. Stocchetti et al. ${ }^{11}$ also supported these findings. Conversely, Milanchi et al. ${ }^{12}$ reported that there was no substantial increase in intracranial pressure in patients having a tracheostomy. So according to the existing literature, it is still uncertain whether the early tracheostomy is more beneficial than late tracheostomy.

The purpose of this study was to analyze the facts that whether early tracheostomy has more fruitful results as compared to late tracheostomy in patients presenting with head injuries and decreased the level of consciousness. In Pakistan, where the number of head injuries is increasing with the time, this study will help the clinicians in adopting early and better treatment and management plan for the patients presenting in emergency and neurosurgery department.

\section{MATERIAL AND METHODS}

\section{Study Design}

This randomized controlled trial (RCT) study was conducted in the department of neurosurgery, Lahore General Hospital Lahore from March 2018 to August 2018, after taking approval from the ethical committee.

\section{Inclusion Criteria}

A total of 130 patients was included. Patients > 18 years of age, presenting with head injuries and conscious level $\leq 9$ according to Glasgow coma scale, admitted in ICU, on mechanical ventilation and having no history of pulmonary infection on chest $\mathrm{x}$-ray were included in the study.

Informed consent was taken from the legal representative of each patient.

\section{Exclusion Criteria}

Patients with GCS > 9, patients in whom tracheostomy was contra-indicated, patients who required emergency tracheostomy and patients with respiratory failure were excluded from this study. Patient who refused concent for this study.

\section{Data Collection}

Demographic data of the patients were collected. Patients were then randomized with a ratio of $1: 1$ using a lottery method. Early tracheostomy (Group - I) was performed within three days of admission and late tracheostomy (Group-II) was performed after three days i.e. $7^{\text {th }}$ to $10^{\text {th }}$ day or later. Tracheostomy was performed according to the standard procedures. Details about the tracheostomy i.e. timings, immediate and late complications were noted. Data regarding acute physiology, age and chronic health evaluation II (APACHE II) was gathered during the first twentyfour hours. Regular data on respiratory support was documented. Data of medicines including, sedatives and antibiotics were recorded. The total number of days since ventilation, tracheostomy, weaning, discharge from the ICU and hospital were noted. Complications and mortality were noted.

\section{Data Analysis}

All the data was entered and analyzed with SPSS 23.0. Quantitative variables were presented as mean and standard deviation, qualitative variables were presented as numbers and percentages Shapiro-Wilk test was used in order to check the normality of the data. Suitable statistical techniques were used. In order to analyze the associations between qualitative variables, the Chi-square test was applied. A $p$-value of $\leq 0.05$ was considered significant.

\section{RESULTS}

The mean age of the patients was $33.13 \pm 2.53$ years with a minimum age of 28 years and the maximum age of 38 years. There were 84 males $(64.61 \%)$ and 46 females $(35.38 \%)$ in the study. The mean age of male patients was $33.14 \pm 2.46$ years and female patients were $33.11 \pm 2.68$ years. The mean age in group I, i.e., in early tracheostomy group was $32.71 \pm 2.46$ years and in group II i.e. late tracheostomy group was 33.55 \pm 2.55 years. The mean Body Mass Index (BMI) of group I patients was $25.54 \pm 1.70 \mathrm{~kg} / \mathrm{m}^{2}$ and of group II was $25.45 \pm 1.71 \mathrm{~kg} / \mathrm{m}^{2}$. 
Table 1: Difference between two groups regarding mechanical ventilation and stay in ICU and Hospital.

\begin{tabular}{|l|c|c|c|}
\hline \multirow{2}{*}{ Variable } & \multicolumn{2}{|c|}{ Mean \pm Std. Deviation } & \multirow{2}{*}{ P value } \\
\cline { 2 - 4 } & Early Tracheostomy & Late Tracheostomy & \\
\hline Mechanical Ventilation Days & $25.68 \pm 2.94$ & $33.37 \pm 3.32$ & 0.000 \\
\hline ICU Stay & $29.42 \pm 2.97$ & $38.54 \pm 3.80$ & 0.000 \\
\hline Hospital Stay & $37.20 \pm 2.98$ & $47.15 \pm 3.84$ & 0.000 \\
\hline
\end{tabular}

Table 2: Comparisons of complications in two groups.

\begin{tabular}{|l|c|c|c|}
\hline \multirow{2}{*}{ Complications } & Early Tracheostomy & Late Tracheostomy & \multirow{2}{*}{ Total } \\
\cline { 2 - 4 } & Cases & Cases & \multicolumn{2}{|c|}{} \\
\hline Sepsis & 10 & 14 & $\mathbf{1 6}$ \\
\hline Pneumothorax & 6 & 10 & $\mathbf{1 0}$ \\
\hline Aspiration & 4 & 6 & $\mathbf{1 1}$ \\
\hline Ventilation associated pneumonia & 3 & 8 & $\mathbf{6 1}$ \\
\hline Total & $\mathbf{2 3}$ & $\mathbf{3 8}$ & \\
\hline
\end{tabular}

The mean GCS score of the group-I patients was $7.00 \pm 0.935$ and of group - II was $7.88 \pm 1.038$. APACHE II score of the early tracheostomy group patients was $22.65 \pm 3.07$ and of late tracheostomy patients was $24.62 \pm 4.62(\mathrm{p}=0.005)$. The difference between the two groups regarding mechanical ventilation days, duration of ICU stay and the total duration of stay in hospital is given in Table 1.

Complications associated with each group were noticed throughout this period. A total of 61 patients (46.92\%) including 23 cases from an early tracheostomy group and 38 cases from a late tracheostomy group suffered from different kinds of complications i.e. pneumothorax, sepsis, ventilation associated pneumonia and aspiration (Chi-square = $0.693, p=0.875)$ (Table 2). Regarding the mortality of the patients, in early tracheostomy group, $4(3.08 \%)$ patients suffered from mortality and in late tracheostomy group, 7 (5.38\%) patients suffered from mortality $($ Chi-square $=0.804, p=0.344)$.

\section{DISCUSSION}

According to the studies, it was suggested that early tracheostomy is better than a late tracheostomy in case of dependency of the patients on mechanical ventilation. Early tracheostomy results in a shorter duration of hospital stay. Rumbak et al. ${ }^{9}$ and Flaatten et al. ${ }^{1}$ have stated in their studies the shorter duration of mechanical ventilation in patients who underwent tracheostomy during initial days of hospitalization or admission in ICU. Our study also suggested the similar findings in case of dependency on mechanical ventilation i.e. $25.68 \pm 2.94$ days in early tracheostomy and $33.37 \pm 3.32$ in case of late tracheostomy ( $\mathrm{p}=$ 0.000). Zagli et al. ${ }^{14}$ in their study noticed that in patients with early tracheostomy duration of mechanical ventilation was shorter than late tracheostomy $(13.3 \pm 9.6$ and $20.8 \pm 9.2$ days $)$. The point of difference between the studies was the timing of tracheostomy only.

In our study, ICU stay and hospital stay in early tracheostomy $(29.42 \pm 2.97$ and $37.20 \pm 2.98$ days $)$ was significantly shorter than the late tracheostomy (38.54 \pm 3.80 and $47.15 \pm 3.84)$ respectively. Our results are in accordance with the study by Mohamed et al. ${ }^{(15)}$. In this prospective randomized control trial study, it was noted that patients undergoing early tracheostomy were having significantly shorter ICU stay $(\mathrm{p}<0.001)$ and hospital stay $(\mathrm{p}=0.005)$ than patients undergoing a late tracheostomy.

The incidence of complications i.e. intra-operative and post-operative in our study was $46.92 \%$ i.e. 61 patients from both groups. The main complications noticed were sepsis $(\mathrm{n}=24,18.46 \%)$, pneumothorax 
( $\mathrm{n}=16,12.31 \%)$, ventilation associated pneumonia $(\mathrm{n}=10,7.69 \%)$ and aspiration $(\mathrm{n}=11,8.46 \%)$. The complications were seen more in late tracheostomy group $(\mathrm{n}=38)$ than the early tracheostomy group $(\mathrm{n}=$ 23). Our study results are in accordance with the findings of Mahafza et $\mathrm{al}^{16}$ who suggested a higher incidence of complications in patients with late tracheostomy. Rumbak et al. ${ }^{9}$ also stated that patients with early tracheostomy experienced a lower incidence of complications than late tracheostomy group. Regarding the mortality of the patients, our study suggested that there mortality in early tracheostomy group ( $\mathrm{n}=4,3.08 \%)$ was lower than the late tracheostomy group $(\mathrm{n}=7,5.38 \%)$. These findings are in accordance to the study by Mahafza et al. ${ }^{16}$ i.e., incidence of mortality was $26(24.5 \%)$ and death ratio was remarkably higher in late tracheostomy group $(36.1 \%)$ than early tracheostomy group (17.1\%). However, Mohamed et $\mathrm{al}^{15}$ in their study noted no significant statistical difference among early $(n=8$, $40 \%)$ and late tracheostomy group $(n=8,40 \%)$.

\section{CONCLUSION}

According to our study, early tracheostomy among the patients presenting with head injuries and having a GCS score $\leq 9$ was associated with a better outcome in terms of shorter mechanical ventilation duration, shorter ICU and hospital stay, reduced complication rate and a lower mortality ratio.

\section{LIMITATIONS}

We conducted this study on a smaller number of patients $(n=130)$, so a study with a larger number of patients should be conducted.

\section{Additional Information}

Disclosures: Authors report no conflict of interest.

Human Subjects: Consent was obtained by all patients/ participants in this study.

\section{Conflicts of Interest:}

In compliance with the ICMJE uniform disclosure form, all authors declare the following:

Financial Relationships: All authors have declared that they have no financial relationships at present or within the previous three years with any organizations that might have an interest in the submitted work.

Other Relationships: All authors have declared that there are no other relationships or activities that could appear to have influenced the submitted work.
Address for Correspondence:

Dr. Abdul Majid

Department of Neurosurgery, PGMI/Lahore General

Hospital (LGH), Lahore - Pakistan

Email: neurosurgeon1974@gmail.com

\section{REFERENCES}

1. Wright DW, Kellermann A, McGuire LC, Chen B, Popovic T. CDC grand rounds: reducing severe traumatic brain injury in the United States. MMWR Morbidity and mortality weekly report, 2013; 62 (27): 549.

2. Marx J, Walls R, Hockberger R. Rosen's Emergency Medicine-Concepts and Clinical Practice E-Book: Elsevier Health Sciences; 2013.

3. Faul M, Wald MM, Xu L, Coronado VG. Traumatic brain injury in the United States; emergency department visits, hospitalizations, and deaths, 2002-2006. 2010.

4. Hyder AA, Wunderlich CA, Puvanachandra P, Gururaj G, Kobusingye OC. The impact of traumatic brain injuries: a global perspective. Neuro-Rehabilitation, 2007; 22 (5): 341-53.

5. Bhatti JA, Stevens K, Mir MU, Hyder AA, Razzak JA. Emergency care of traumatic brain injuries in Pakistan: a multicenter study. BMC emergency medicine, 2015; 15 (2): S12.

6. Baron DM, Hochrieser H, Metnitz PG, Mauritz W. Tracheostomy is associated with decreased hospital mortality after moderate or severe isolated traumatic brain injury. Wiener klinische Wochenschrift, 2016; 128 (11-12): 397-403.

7. Lesnik I, Rappaport W, Fulginiti J, Witzke D. The role of early tracheostomy in blunt, multiple organ trauma. The American Surgeon, 1992; 58 (6): 346-9.

8. D'amelio L, Hammond J, Spain D, Sutyak J. Tracheostomy and percutaneous endoscopic gastrostomy in the management of the head-injured trauma patient. The American surgeon, 1994; 60 (3): 180-5.

9. Rumbak MJ, Newton M, Truncale T, Schwartz SW, Adams JW, Hazard PB. A prospective, randomized, study comparing early percutaneous dilational tracheotomy to prolonged translaryngeal intubation (delayed tracheotomy) in critically ill medical patients. Critical care medicine, 2004; 32 (8): 1689-94.

10. Kocaeli H, Korfalı E, Taşkapılıoğlu Ö, Özcan T. Analysis of intracranial pressure changes during early versus late percutaneous tracheostomy in a neurointensive care unit. Acta neurochirurgica, 2008; 150 (12): 1263-7.

11. Stocchetti N, Parma A, Songa V, Colombo A, Lamperti M, Tognini L. Early translaryngeal tracheostomy in patients with severe brain damage. Intensive care medicine, 2000; 26 (8): 1101-7. 
12. Milanchi S, Magner D, Wilson MT, Mirocha J, Margulies DR. Percutaneous tracheostomy in neurosurgical patients with intracranial pressure monitoring is safe. Journal of Trauma and Acute Care Surgery, 2008; 65 (1): 73-9.

13. Flaatten H, Gjerde S, Heimdal J, Aardal S. The effect of tracheostomy on outcome in intensive care unit patients. Acta anaesthesiologica scandinavica, 2006; 50 (1): 92-8.

14. Zagli G, Linden M, Spina R, Bonizzoli M, Cianchi G, Anichini $\mathrm{V}$, et al. Early tracheostomy in intensive care unit: a retrospective study of 506 cases of video-guided
Ciaglia Blue Rhino tracheostomies. Journal of Trauma and Acute Care Surgery, 2010; 68 (2): 367-72.

15. Mohamed KAE, Mousa AY, ElSawy AS, Saleem AM. Early versus late percutaneous tracheostomy in critically ill adult mechanically ventilated patients. Egyptian Journal of Chest Diseases and Tuberculosis, 2014; 63 (2): 443-8.

16. Mahafza T, Batarseh S, Bsoul N, Massad E, Qudaisat I, Al-Layla AEe. Early vs. late tracheostomy for the ICU patients: Experience in a referral hospital. Saudi journal of anaesthesia, 2012; 6 (2): 152.

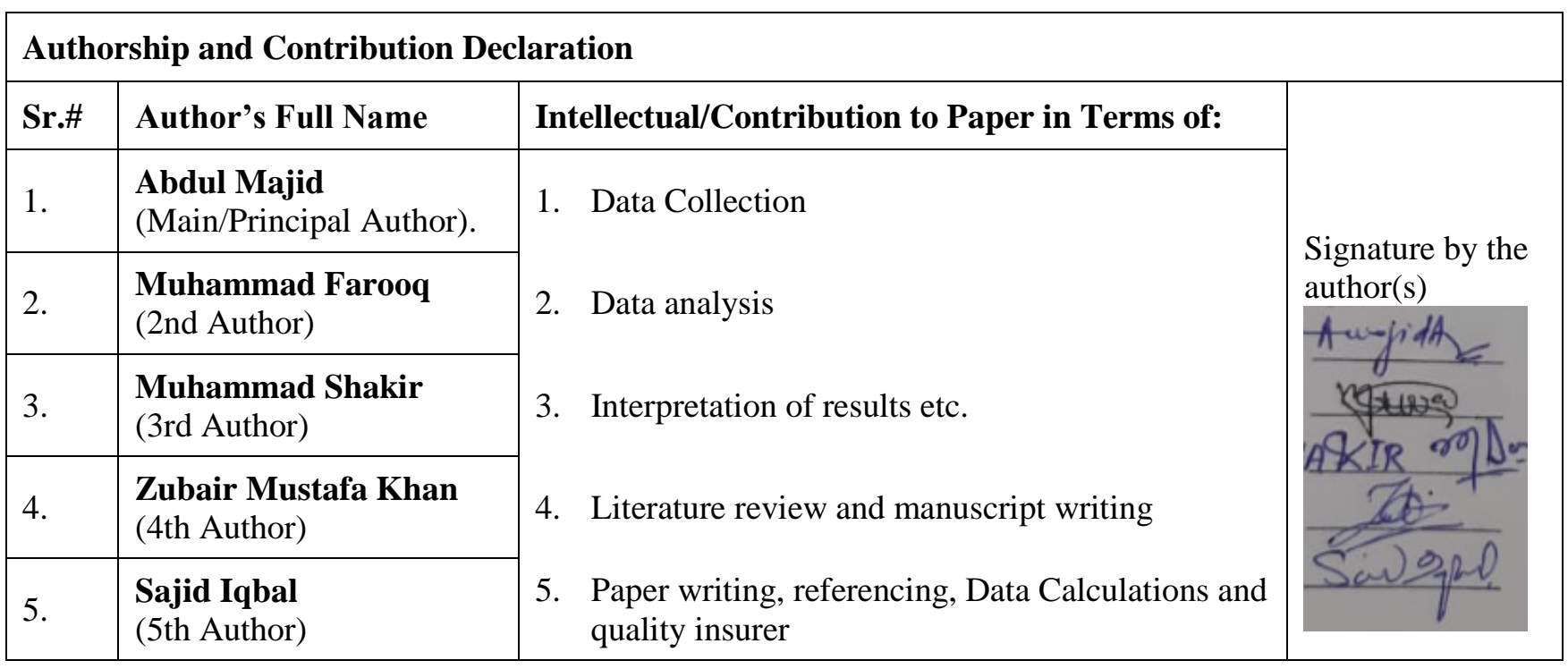

Date of Submission: 06-07-2019

Date of Revision: 30-07-2019

Date of Online Publishing: 25-09-2019

Date of Print: 30-09-2019 